
\title{
25 Research Square \\ Effects of different autophagy inhibitors on treatment with ATO/ATRA in KG-1 and HL-60 leukemia cells
}

\section{Atousa Haghi}

Tehran University of Medical Sciences

Mahdieh Salemi

Tehran University of Medical Sciences

\section{Aila Fakhimahmadi}

National Institute for Genetic Engineering and Biotechnology

\section{Mahnaz Mohammadikian}

Tehran University of Medical Sciences

\section{Hassan Yousefi}

Louisiana State University Health Sciences Center

\section{Marveh Rahmati}

Tehran University of Medical Sciences

\section{Saeed Mohammadi}

Tehran University of Medical Sciences

\section{Ardeshir Ghavamzadeh}

Tehran University of Medical Sciences

\section{Mohammad Amin Moosavi}

National Institute for Genetic Engineering and Biotechnology

Mohsen Nikbakht ( $\square$ m-nikbakht@sina.tums.ac.ir)

tehran university of medical science https://orcid.org/0000-0001-6621-5424

\section{Research article}

Keywords: Autophagy, AML, ATO, ATRA

Posted Date: March 26th, 2020

DOI: https://doi.org/10.21203/rs.3.rs-19050/v1

License: (c) (i) This work is licensed under a Creative Commons Attribution 4.0 International License.

Read Full License 


\section{Abstract}

Background : Few current autophagy inhibitors may have beneficial effects for acute myeloid leukemia (AML) patients in clinical phases. However, there is a strong need to figure out which settings should be activated or inhibited in autophagy pathway to prevail drug resistance and improve current treatment options in leukemia. This study aimed to compare the effects of 3 well-known inhibitors of autophagy (3MA, BafA1 and HCQ) in human leukemia KG1 and HL-60 cells exposed to ATO and/or ATRA.

Methods : Cell proliferation and cytotoxicity of KG-1 and HL-60 cells were examined by MTT assay. Autophagy was studied by evaluating the development of acidic vesicular organelles, and the autophagosomes formation was investigated by acridine orange staining and transmission electron microscopy. Gene and protein expression levels of autophagy markers ( ATGs, p62/SQSTM1 and LC-3B) were also performed by qPCR and western blotting, respectively. The rate of apoptosis (annexin-V/PI staining) and cell cycle were evaluated using flow cytometry.

Result: We compared the cytotoxic and apoptotic effects of arsenic trioxide (ATO) and/or all-trans retinoic acid (ATRA) in KG1 and HL-60 cells, and demonstrated that some autophagy markers can be upregulated in this context. Also, autophagy blockers HCQ and/or BafA1 could potentiate the cytotoxic effects of ATO/ATRA, which were more pronounced in KG-1 cells compared with HL-60 cell line.

Conclusion: This study showed the involvement of autophagy during treatment of KG1 and HL-60 cells with ATO/ATRA.also, this study propose was to propose that combination therapy of ATO/ATRA with the autophagy inhibitor HCQ can be considered as a more effective strategy for targeting leukemic KG-1 cells. Key words: Autophagy, AML, ATO, ATRA

\section{Introduction}

Macroautophagy, hereafter referring as autophagy, is a catabolic signaling pathway as a result of stress conditions or nutrient limitations, to maintain cellular metabolism and organelle integrity (1-3). Although autophagy is a homeostatic mechanism for intracellular recycling and the removal of damaged organelles or malfolded proteins. During autophagy, cargos are sequestrated into double-membrane vesicles, called autophagosomes, which then fuse with lysosomes for subsequent degradation or recycling of their contents $(4,5)$. Autophagy can confer stress tolerance, limit trauma, and sustain viability in harsh conditions. Deficiency in autophagy has been implicated in various diseases such as aging, neurodegeneration, liver disease, and mainly in cancer (6). The function of autophagy as a prosurvival has been determined at the cellular and organismal level in different situations such as during endoplasmic reticulum stress, nutrient or growth factor deprivation, microbial infection, and the diseases characterized by the accumulation of protein aggregates. This pro-survival function is known to be adaptive; however, in the context of cancer, it might significantly become abnormal. Metabolic stress is a common specification of the tumor niche, and most of the chemotherapeutic agents promote cellular stress. Therefore, an area of intense investigation have been focused on whether autophagy-dependent 
survival should be blocked in these conditions to enhance tumor-cell death (7). Therefore, an area of intense investigation has been focused on whether autophagy-dependent survival should be blocked in these conditions to enhance tumor-cell death.

Acute myeloid leukemia ( $A M L)$ is characterized by accumulation of abnormal hematopoietic progenitor cells and infiltration of blood, bone marrow, and other tissues(8). The inhibited cell differentiation can prevent the maturation of the progenitor cells, and subsequently prevent undergoing apoptosis(9). The hypoxic bone marrow niche in AML contributes to chemotherapy resistance, and subsequently allows persistence of minimal remaining malignant cells after chemotherapy, and finally leads to relapse. While the hypoxic and metabolically reprogaremmed niche are in the bone marrow, contact with other cellular elements of the bone marrow is anticipated to activate autophagy in leukemia cells(10).

Recent evidence revealed that impaired autophagy could alter hematopoietic stem cells (HSCs) to cells with preleukemic state phenotypes(11). In addition, myeloid leukemia have reported that leukemic cells require functional autophagy during leukemia maintenance $(12,13)$. On the other hand, other studies have indicated that the autophagy machinery in AML might be disrupted, due to the accumulation of damaged mitochondria and increased levels of reactive oxygen species (ROS), which could potentially promote the leukemic transformation $(14,15)$. Moreover, autophagy can be utilized as an escape mechanism by leukemic cells after treatment with chemotherapeutics such as HDAC and mTOR inhibitors $(16,17)$.

Arsenic trioxide (ATO) displays potent anti-leukemic effects and apoptosis-inducing therapy. accordingly, targeting the combinatorial strategy is recognized as a promising therapeutic approach in AML (18-20). The predominant form of retinoids, which is all-trans retinoic acid (ATRA), has been successfully used to treat acute promyelocytic leukemia (a particular AML subtype, which is known by the translocation $t(15,17)$ encoding for the oncogene-retinoic acid receptor alpha (PML-RARA) fusion protein), which induces neutrophil differentiation of leukemic blast cells $(21,22)$. ATRA and ATO is curative and standard regimen in the treatment of acute promyelocytic leukemia (APL). ATO and ATRA were effective in both the mouse and human model of AML cells, and their combination evidenced powerfully and precious treatment for AML subtypes in vitro. According to these data we assume that ATO, ATRA and their combination could be the possible therapeutic strategy which target different susceptibilities for other subset of $\mathrm{AML}(23)$.

Although different basic studies and clinical trials evaluating effects of autophagy modulators in cancers have been carried out, there is a lack of information which settings in autophagy pathway should be activated or inhibited to improve current treatment options in leukemia (24). The aim of our research is to study a possible role of autophagy and its therapeutic importance during treatment with ATO/ATRA regime in KG1 and HL-60 leukemia cell lines. We found that ATO/ATRA treatment induces autophagy in these cells and autophagy blockage at the late stage, particularly by means of hydroxyquinoline (HCQ), could enhance chemotherapy effects in KG1 cells.

\section{Material And Methods}




\section{Cell culture}

The human acute myeloid leukemia cell lines (KG-1 and HL-60) were obtained from the National Cell Bank of Iran at Pasteur Institute of Iran. KG-1 and HL-60 were grown in suspension using RPMI 1640 medium containing $10 \%$ heat-inactivated fetal bovine serum, $100 \mathrm{mg} / \mathrm{mL}$ streptomycin, and $100 \mathrm{U} / \mathrm{mL}$ penicillin at $37{ }^{\circ} \mathrm{C}$ in a humidified atmosphere of $95 \%$ air and with $5 \% \mathrm{CO}_{2}$. The passage number for all tests was between 3 and 5 .

\section{Proliferation Assay}

The 3-(4,5-dimethylthiazol-2-yl)-2,5-diphenyltetrazolium bromide (MTT) assay was used to evaluate inhibition of cell proliferation potential of ATO, ATRA, 3-Methyladenine (3-MA), HCQ, and bafilomycin A1 (Baf-A1). KG-1 and HL-60 cells were cultured at $5^{\star} 10^{\wedge} 3$ cells/well in 96 -well plate by various concentration of compounds ( $24 \mathrm{~h} \& 48 \mathrm{~h}$ ) and inhibitors $(48 \mathrm{~h})$, and then were incubated at $37^{\circ} \mathrm{C}$. At the end of the determined time, $10 \mathrm{~mL}$ of MTT was added, and cells were incubated for another $4 \mathrm{~h}$. Finally, $100 \mathrm{~mL}$ of DMSO was added to each well, which were totally 96 -well plates. The rate of cell proliferation inhibition was achieved by scanning with ELISA reader with a $570 \mathrm{~nm}$ filter.

\section{Apoptosis Assay}

KG-1 and HL-60 cell lines were seeded at a density of $3 \times 10^{\wedge} 5$ cell/well in 12 well culture plate, and were then incubated for 48 hours in the absence and presence of ATO, ATRA, 3-MA, HCQ, Baf-A1, and their combinations for $48 \mathrm{~h}$. To assess the percentage of cell apoptotic ratio induced by treated compounds, fluorescein-conjugated Annexin V (Annexin V-FITC) staining assay was performed in terms of the manufacturer protocol. The percentage of apoptosis was evaluated as a percentage of the Annexin $\mathrm{V}+\mathrm{PI}$ - cells through flow cytometry using BD flow cytometer instrument, and was analyzed with flowjo (Tree Star Inc., version 9.6.3, USA) program.

\section{Dna Cell Cycle Analysis}

KG-1 and HL-60 cells were treated with indicated concentrations of ATO, ATRA, 3-MA, HCQ, Baf-A1, and their combinations for $48 \mathrm{~h}$, and were then fixed in $70 \%$ in ethanol washed in PBS, resuspended in $1 \mathrm{ml}$ of PBS containing $0.5 \mathrm{mg} / \mathrm{ml}$ of RNase $A$ and $0.01 \mathrm{mg} / \mathrm{ml}$ of PI for half an hour at room temperature in darkness. Flow cytometric analysis of KG-1 cells was performed using a FACScan flow cytometer (Becton Dickinson Immunocytometry Systems), and analyzed with flowjo software. The cell fraction could be predicted from hypodiploid sub-G0/G1 DNA fraction.

\section{Rna Isolation And Real-time Pcr}


KG- 1 and HL-60 cell lines were seeded at a density of $3 \times 10^{\wedge} 5$ cell/well in 12 well culture plates, and were then incubated for 48 hours in the absence and presence of ATO, ATRA, 3-MA, HCQ, Baf-A1, and their combinations for $48 \mathrm{~h}$. RNA was extracted from KG-1 and HL-60 cells using the TRI pure (Roche Applied Science, Germany), with respect to the manufacturer instructions. The RNA pellets were reconstituted in DEPC treated water. The quantity and quality of total RNA were specified by spectro-photometrically using Nanodrop ND-1000 (Nanodrop Technologies, Wilmington, DE) at 260 and $280 \mathrm{~nm}$. First-strand complementary DNAs (cDNA) synthesis were oppositely transcribed from 1-2 $\mu \mathrm{g}$ of total RNA by the use of cDNA synthesis kit (Takara Bio Inc., Otsu, Japan) according to the manufacturer instructions. Real-time PCR was performed using a standard SYBR Green PCR protocol on Light Cycler 96 instrument (Roche). Then, the cDNA concentration was normalized in a series of PCR using HPRT and GAPDH primers. Also, the normalized cDNAs were subjected to amplification. The levels of HPRT mRNA expression were used to estimate the relative expression levels. The comparative mean cycle threshold value (Ct) method was used to compute relative expression values. The primers and their corresponding amplicon lengths are presented in Table 1.

Table 1

Primer for Real-Time PCR

\begin{tabular}{|lll|}
\hline Primer & Sequence & Ref \\
\hline GAPDH & $\begin{array}{l}\text { TGAACGGGAAGCTCACTGG } \\
\text { TCCACCACCCTGTTGCTGTA }\end{array}$ & $(25)$ \\
\hline LC3-II (MAP1LC3) & $\begin{array}{l}\text { GCTATAAATTCTTTGCTGACCTGCTG } \\
\text { AATTACTTTTATGTCCCCTGTTGACTGG } \\
\text { TTGAGCTGTAATATTCGAGAGC }\end{array}$ & $(26)$ \\
\hline BECN1 & $\begin{array}{l}\text { AGCTGCCGTTATACTGTTCTG } \\
\text { ACTGCCTCCTGTGTCTTCAATCTT }\end{array}$ & $(27)$ \\
\hline ULK1 & $\begin{array}{l}\text { TCGAGTTCTCCCGCAAGG } \\
\text { CGTCTGAGACTTGGCGAGT }\end{array}$ & $(28)$ \\
\hline ATG7 & $\begin{array}{l}\text { AGGCGCACTACCGCGAT } \\
\text { CGTCACTGGAAAGGCAACC }\end{array}$ \\
\hline ATG12 & $\begin{array}{l}\text { GGCCTTTGAGGAATTTTTTGG } \\
\text { ACGTCTCTAGCTCCCTGCATG }\end{array}$ \\
\hline CASP3 & $\begin{array}{l}\text { TGAATCAGTCCTTTGCCCCT } \\
\text { CATGCCTGGGATTTGCAGT }\end{array}$ \\
\hline
\end{tabular}




\section{Detection Of Acidic Vesicular Organelles During Autophagy Formation}

The development of acidic vesicular organelles (AVOs) is one of the hallmarks of autophagy, which can be determined by acridine orange (AO) staining of the cells. KG-1 and HL-60 cells staining with AO $(100 \mu \mathrm{g} / \mathrm{ml})$ were accomplished based on the published procedures(32). Cells were resuspended by PBS, and then by adding $\mathrm{AO}$. The fluorescence of $\mathrm{AO}$ shifts from green to red within acidic components of the cells. Photos were obtained using a fluorescence microscope (559-nm, Axioscop, Carl Zeiss, Germany).

\section{Western Blotting Analysis}

Cells were treated to ATO, ATRA, 3-MA, HCQ, Baf-A1, and their combinations for the selected concentrations and time periods. Treated cells were washed with ice-cold PBS, and lysed in ice-cold cell RIPA lysis, extraction buffer (CMG Co, Esfehan, Iran), and a cocktail of protease inhibitors (CMG Co, Esfehan, Iran). Protein concentration was quantified using the Bradford (1976) assay method. The Equal amounts of total extracted cellular proteins $(50 \mathrm{mg}$ ) were used for SDS polyacrylamide gel electrophoresis and subjected to western blotting by polyvinylidene difluoride membranes (Whatman, UK). Subsequently, the transferred membranes were blocked by non-fat dry milk powder (5\%) in TrisBuffered Saline and $0.05 \%$ Tween-20 (TBST) for $90 \mathrm{~min}$ at room temperature, and were then incubated with the primary antibodies anti-LC3B (purchased from Abcam), and anti-GAPDH and anti-SQSTM1/P62 (purchased from Santa Cruz Biotech, USA). All the antibodies were incubated in $2 \%$ skim milk at $4{ }^{\circ} \mathrm{C}$ overnight. Membranes were washed three times in TBST $(0.2 \%)$, and were then incubated for $2 \mathrm{~h}$ at room temperature, and anti-rabbit secondary antibody was used for LC3II (Sigma-Aldrich), and anti-mouse IgG secondary antibody for GAPDH (purchased from Santa Cruz Biotech, USA).

\section{Transmission Electron Microscopy}

For transmission electron microscopy (TEM) measurement, each sample was fixed with $2 \%$ glutaraldehyde, and was then post-fixed with $1 \%$ Osmium tetroxide (stock solution 1-2\%) dissolved in phosphate buffer $(0.1 \mathrm{M})$. After that, pure and fresh resin was used for embedding and polymerizing. Specimens were stained with $2 \%$ aqueous uranyl acetate, and lead citrate to contrast staining. Finally, all of the thin samples were observed by TEM (Philips EM208S) at an acceleration voltage of $100 \mathrm{kV}$.

\section{Statistical analysis}

Statistical analysis was performed by GraphPad prism 5 and R programming. The data were expressed as the mean \pm standard deviation (SD). The difference between two mean values was analyzed using one-way ANOVA, and was considered to be statistically significant defined at $* P<0.05,{ }^{\star} P<<0.01$, and $\star \star \star \mathrm{P}<0.001$. 


\section{Result}

\section{The cytotoxic effects of ATO and ATRA in KG1 and HL-60 cells}

we evaluated the effect of different concentrations of ATO and/or ATRA, alone or in combination with autophagy inhibitors, on proliferation and viability of KG-1 and HL-60 cells after $24 \mathrm{~h}$ and $48 \mathrm{~h}$. The $50 \%$ inhibitory concentrations (IC50) of ATO and IC30 of ATRA were determined using MTT assay (Fig. 1). For example, IC50 for ATO were $1.61 \mu \mathrm{M}$ and $1 \mu \mathrm{M}$ in KG-1 and HL-60 cells, respectively, whereas IC30 for ATRA was approximately $700 \mathrm{nM}$ in both cells. In addition, our result indicated that combining ATO with ATRA further reduced the cell proliferation (up to 60\%) in KG-1 and HL-60 cell lines, in comparison to each monotherapy (Fig. 1). Therefore, ATO/ATRA is more potent inhibitor of the viability of leukemia cells compared to each monotherapy.

\section{The Autophagic Effects Ato/atra In Kg-1 And HI-60 Cells}

To see the importance of autophagy in ATO/ATRA treatment, we evaluate AVO formation by the lysosomotropic and $\mathrm{pH}$-sensitive $\mathrm{AO}$. The results showed that the red fluorescent increased in both $\mathrm{KG}-1$ and $\mathrm{HL}-60$ cells treated with Baf-A1 and HCQ, indicating the development of AVOs (Fig. 2a). Also, The TEM results confirmed the increased level of autophagosomes in both cells exposed to ATO/ATRA (Fig. 2c).

Then, we examined the gene and protein expression levels of key ATGs and autophagy marker protein LC3B and P62 by qPCR and western blotting (Fig. 2b). Upon induction of autophagy, LC3B-I (19 kDa) is converted to LC3B-II (17 kDa), and then conjugated with phosphatidylethanolamine (PE) within autophagic membranes. Since the rate of LC3B correlates well with the number of autophagosomes, this features of the conversion of LC3 could be used to monitor autophagic flux(33). P62, also known as sequestosome 1 (SQSTM1) in humans, directly interact with LC3 to promote the formation of autophagosome. The occurrence of autophagy was further evaluated by the mRNA expression of typical ATGs by real-time PCR. We observed the up-regulated the mRNA expression of BECN1, LC3B, P62, ATG12 and ULK in KG-1 ATO/ATRA treated cells compared with control cells (Fig. 3a). After treatment of KG-1 cells for $48 \mathrm{~h}$, we observed that ATO/ATRA with a combination of HCQ, up-regulated the mRNA expression of LC3B, P62, CASP3, ATG12, and ULK; whereas they down-regulated BECN1 and ATG7 in comparison with control. After treatment of HL-60 cells for $48 \mathrm{~h}$, we observed that ATO/ATRA with a combination of HCQ, up-regulated the mRNA expression of LC3B, P62, CASP3, ATG12, and ATG7; whereas they down-regulated BECN1 and ULK in comparison with control. Moreover, combination of BafA1 with ATO/ATRA up-regulated the mRNA expression of BECN1, LC3B, P62, CASP3, ATG12, and ULK; however, they down-regulated ATG7 in KG-1 cells compared to control (Fig. 3b). While $48 \mathrm{~h}$ treatment with ATO/ATRA increased gene expression levels LC3B, we observed no significant change at the protein levels of LC3B in both cells. However, the protein levels of LC3B and P62 were clearly increased after 
combination of ATO/ATRA with autophagy inhibitor HCQ (Fig. 2b). In addition, TEM confirmed that after treating KG-1 and HL-60 cells with selected doses of ATO/ATRA, the cells displayed the accumulation of autophagosomes after $48 \mathrm{~h}$. Additionally, other morphological futures such as condensation of chromatin, a common nuclear morphology of apoptosis, was also observed in KG-1 cells (Fig. 2c)

Effects of ATO/ATRA in combination with autophagy inhibitors on proliferation and cell cycle pattern of KG-1 and HL-60

We next evaluated changes in proliferation and cell cycle pattern after treatment with ATO/ATRA either alone or in combination with the autophagy inhibitors 3-MA, HCQ and BafA1. As shown in Fig. 4, the changes in the proportion of cells at the G0/G1 phase of the cell cycle in KG-1 cells were: control: $38.94 \%$, HCQ + ATO/ATRA: 61\%, BafA1 + ATO/ATRA: 48.01\% and 3-MA + ATO/ATRA: 48.75\%. As shown in Fig. 5, cell cycle changes in HL-60 were: control: 67.50, HCQ + ATO/ATRA: 51.88 BafA1 + ATO/ATRA: 54.93 and 3-MA + ATO/ATRA: $54.36 \%$. These data showed that the anti-proliferative effects of autophagy inhibitors in combination with ATO/ATRA is generally followed by the cell-cycle arrest. We observed an interesting pattern for $\mathrm{G} 0$ and $\mathrm{G} 1$ in HL-60 cells. ATO/ATRA could decrease $\mathrm{G} 0$ and the cells enter to $\mathrm{G} 1$ but for KG-1 cells both the rate of $\mathrm{G} 0$ and $\mathrm{G} 1$ increased after treatment by ATO/ATRA.

Effects of ATO/ATRA in combination with autophagy inhibitors on apoptosis in KG-1 and HL-60 cells

To determine the mode of cell death induced by ATO/ATRA, we studied the occurrence of apoptosis as a typical type of programmed cell by Annexin/PI double staining and CASP3 expression. We observed a profound induction of apoptosis in both cells, and also the level of mRNA expression for CASP3 significantly increased in cells treated with Baf-A1/ATO/ATRA and HCQ/ATO/ATRA in both KG-1 and HL60 cells (Fig. 3). Our data exhibited that, HCQ in combination with ATO/ATRA could significantly increase apoptotic $(75.32+1.72 \%)$, when compared with control $(8.64+0.26 \%)$ and ATO/ATRA $(54.58+0.52 \%)$. Baf-A1 in combination with ATO/ATRA increased apoptotic $(61.3+1.72 \%)$ when compared with control and ATO/ATRA. 3-MA in combination with ATO/ATRA slightly $(60+1.2 \%)$ increased apoptotic, in comparison with ATO/ATRA, and no significant necrotic cells were in the groups exposed to ATO/ATRA $(10.8 \%+0.65 \%)$ alone or in association with $3-\mathrm{MA}(7.5+0.94)$, HCQ $(6.77+0.36)$, and BafA1 $(5.09+0.52)$ in KG-1 cells. Thus, our data demonstrated that HCQ and BafA1 in combination with ATO/ATRA were more effective than 3-MA in KG-1 cell line (Fig. 6). These results demonstrate that the blockage of autophagy flux is more associated to apoptosis other than inhibition of autophagy induction (3-MA). In contrast with KG-1, we observed no detectable increase in apoptotic effects of ATO/ATRA in combination with autophagy inhibitors in HL-60 cells (Fig. 7).

\section{Discussion}

In this study, we showed a critical role of autophagy during treatment with the combination of ATO/ATRA. Also, we indicated that the synergistic effect of autophagy inhibitors HCQ, 3-MA, and Baf-A1 can enhance the beneficial outcomes of this therapeutic regime in leukemia cells. These inhibitors can block autophagy at different stages during the cytotoxic effects of ATO/ATRA. Therefore, it is important to 
investigate their unique mechanisms and molecular pathways in order to gain more insight into autophagy inhibitors while utilizing ATO/ATRA combinatorial approach.

Autophagic responses lead to the maintenance of homeostasis and adaptation to stress in normal and cancer cells(34). It has also been recognized as a common pro-survival mechanism among numerous tumor types. The association between autophagy and tumor cell survival can be explained via autophagy function in retaining cells from undergoing programmed cell death. This provides a logical rationale for autophagy inhibition promoting response to other agents(35). The results of published clinical trials exhibit evidence for the safe use of HCQ as cancer therapies(36, 37). Although autophagy might be considered as functional in various cancer cells and may be needed for the response to stresses, some cancer cells may be specifically associated with autophagy, even in the absence of added stress. This phenomenon is called autophagy-dependence, and is also crucial because it has been identified in some studies that only autophagy-dependent cancer cells is responding to autophagy inhibitors. Expectedly, drug synergy between pharmacological autophagy inhibitors and other anticancer compounds might exert its effects through an autophagy-dependent manner in cancer cells, and it is probable that the combination of identical agents was occasionally worked antagonistically in autophagy-independent cancer cells $(35,38,39)$.

In hematological malignancies, autophagy acts as both tumor-suppressor and chemoresistance inducer. Nowadays, It is known that, based on both type of progenitor cells and the state of leukemia, autophagy might play contradictory roles(40). Different studies have shown that leukemic blasts and LSCs have the ability of applying autophagy to reply to the specific energetic needs during exponential cell proliferation to neutralize chemotherapeutic stress as a survival mechanism. For instance, it has been confirmed that, in chronic myeloid leukemia (CML), patient-derived LSCs contain high levels of gene expression of basal autophagy compared to mature cells, and this targeting autophagy by pharmacological or genetic inhibition may result in reduced leukemic cell viability and improved sensitivity to common chemotherapy(41-43).

Our data indicated that the autophagic pathway involved in cell death mechanism in KG-1 during response to dual-agents treatment of ATO/ATRA. Combination of ATO/ATRA with HCQ or Baf-A1 inhibited cell proliferation, and induced apoptosis in KG-1 cells. Moreover, electron microscopy imaging confirmed rapid induction of cell death with autophagic features. The extent of cell death and phenotypes of HCQ and Baf-A1-induced autophagic markers such as an increase in microtubule-associated protein LC3-I conversion to LC3-II, BECN1, and autophagosome were considerably greater in KG-1 cells.

ATO and ATRA have major impacts on the treatment of patients with leukemia. However, AML cells can respond to ATO and ATRA in different ways ranged from activation of cell death to the initiation of survival pathways such as autophagy(44).

The relationship between apoptosis and autophagy is complicated in cancers. Apoptosis and autophagy could regulate each other, mostly during an inhibitory procedure. However, somewhen autophagy may 
favor the activation of apoptosis. Apoptosis may initiate with autophagy, and autophagy may end with apoptosis(45).

Different studies linked autophagy genes to programmed cell death. For instance, in human glioblastoma, blockage of autophagy genes ATG1 or ATG5 hindered the cytotoxic effect of cannabinoids, which can increase the autophagy-dependent cell death with mTORC1-dependent pathway(46).

In the central nervous system, ATG7 deficiency preserved neurons from caspase-dependent and caspaseindependent cell death after hypoxic-ischemic brain harm(47).

Li et al. demonstrated that inhibition of early steps of autophagy via 3-MA or BECN1 knockdown reduced the cytotoxic effect of ATO in glioblastoma multiforme cell lines. On the other hand, blockage of autophagy flux at the final stage by chloroquine (CQ) or Rab7 knockdown promoted the cytotoxicity of ATO, and resulted in the accumulation of degradative autophagic vacuoles and apoptosis(24).

Brigger et al. demonstrated that ATRA activated autophagic flux in retinoid-sensitive SKBR3 breast cancer cells by RARa, while autophagy induction was not observed in the retinoid-resistant MDA-MB453 breast cancer cell line. They assumed that ATRA can activate autophagy only in breast cancer cells, which are not terminally differentiated. Using 3-MA as a specific inhibitor of autophagy results in enhanced apoptosis(48). Wang et al. showed a relationship between autophagy activation and ATRA-induced degradation of PML-RARa fusion protein, which may lead to myeloid cell differentiation. Moreover, they proposed human p62 as a direct moderator of ATRA-induced degradation of RARa, and supplied mechanistic insight into the role of p62 in regulating cell differentiation. Also, inhibition of autophagy elements including ATG1, ATG5, PI3KC3, and 3-MA by shRNA, blocked PML-RARa degradation; and consequently, blocked granulocytic differentiation of human myeloid leukemic cells(49).

Bonapace et al. observed a partial decrease in dexamethasone cytotoxicity using 3-MA or nec-1 in an appropriate GC-sensitive cell lines. However, they detected no effect of 3-MA in primary ALL cells, in which caspase-dependent cell death dominated. They identified autophagy as a primary and limiting step to steroid sensitization by obatoclax in GC-resistant cells, and emphasized on the importance of considering the cellular context during designing the strategies to target autophagy for cancer therapy(50). Kim et al. demonstrated the HCQ-induced dose-dependent and time-dependent cell death in cytosine arabinosideresistant cells compared to cytosine arabinoside-sensitive cell lines. Although, apoptotic cell death and caspase activation in U937/arabinoside-resistant cells were enhanced by HCQ, their results demonstrated that HCQ induced autophagy blockade. The extent of cell death and features of HCQ-induced autophagic markers such as an increase in LC3I conversion to LC3-II, BECN1, and ATG5 were considerably greater in U937/arabinoside-resistant(51). Baquero et al. demonstrated that long-term hematopoietic stem cells isolated from leukemic mice have higher basal autophagy levels, compared to non-long-term hematopoietic stem cells and mature leukemic cells (40).

Folkerts et al. confirmed that AML CD34 + cells were more sensitive to the HCQ, as an autophagy inhibitor, compared to normal bone marrow CD34 + cells. In addition, inhibition of autophagy via knockdown of 
ATG5 or ATG7 operated apoptosis, which was occurred along with promoted expression of p53. They confirmed that targeting autophagy might provide a new therapeutic strategy for the treatment of $\operatorname{AML}(52)$.

\section{Conclusion}

This study shows the involvement of autophagy during treatment of KG1 and HL-60 cells with ATO/ATRA. Autophagy blockers may enhance the beneficial outcomes of this therapeutic regime in leukemia cells. Also, more studies are required to be taken for the purpose of figuring out the critical contexts in which condition autophagy inhibition will be lucrative, and in which it could be detrimental.

\section{Abbreviations}

3-(4,5-dimethylthiazol-2-yl)-2,5-diphenyltetrazolium bromide (MTT)

3-Methyladenine (3-MA)

Acidic vesicular organelles (avos)

Acridine orange (AO)

Acute myeloid leukemia (AML)

Acute promyelocytic leukemia (APL)

All-trans retinoic acid (ATRA)

Arsenic trioxide (ATO)

Bafilomycin A1 (Baf-A1)

Chloroquine (CQ)

Chronic myeloid leukemia (CML)

Hematopoietic stem cells (hscs)

Hydroxyquinoline (HCQ)

Inhibitory concentrations (IC)

Phosphatidylethanolamine (PE)

Reactive oxygen species (ROS)

Sequestosome 1 (SQSTM1) 
Standard deviation (SD)

Transmission electron microscopy (TEM)/p>

\section{Declarations}

Competing interests

The authors declare that they have no competing interests

Funding

This study was performed and funded by Hematology, Oncology and Stem Cell Transplantation Research Center, Tehran University of Medical Sciences.

Authors' contributions

A.H, M.N, H.Y, M.R wrote the article. A.H, M.N, MA.M, M.S, designed the research. A.H, M.S, A.F, M.M.K, performed the research. M.N, MA.M A.H, A.G, H.Y, S.M, M.R analyzed the data.

Acknowledgements

This study was performed and funded by Hematology, Oncology and Stem Cell Transplantation Research Institute, Tehran University of Medical Sciences (Tehran, Iran).

Ethics approval and consent to participate

Not applicable

Consent for publication

Not applicable

Availability of data and materials

The data that support the findings of this study are available from the corresponding author upon reasonable request

Acknowledgements

This study was performed and funded by Hematology, Oncology and Stem Cell Transplantation Research Institute, Tehran University of Medical Sciences (Tehran, Iran).

\section{References}

1.

Torgersen ML, Engedal N, Bøe S-O, Hokland P, Simonsen A. Targeting autophagy potentiates the apoptotic effect of histone deacetylase inhibitors in t (8;21) AML cells. Blood. 2013;122(14):2467-76.

2.

Mizushima N. Autophagy: process and function. Genes Dev. 2007;21(22):2861-73.

3. 
Mizushima N, Yoshimori T, Levine B. Methods in mammalian autophagy research. Cell. 2010;140(3):31326.

4.

Liu L, Yang M, Kang R, Wang Z, Zhao Y, Yu Y, et al. HMGB1-induced autophagy promotes chemotherapy resistance in leukemia cells. Leukemia. 2011;25(1):23.

5.

White E, DiPaola RS. The double-edged sword of autophagy modulation in cancer. Clin Cancer Res. 2009;15(17):5308-16.

6.

Livesey KM, Tang D, Zeh HJ, Lotze MT. Autophagy inhibition in combination cancer treatment. Current opinion in investigational drugs (London, England: 2000). 2009;10(12):1269-79.

7.

Mizushima N, Levine B, Cuervo AM, Klionsky DJ. Autophagy fights disease through cellular self-digestion. Nature. 2008;451(7182):1069-75.

8.

Papaemmanuil E, Gerstung M, Bullinger L, Gaidzik VI, Paschka P, Roberts ND, et al. Genomic classification and prognosis in acute myeloid leukemia. N Engl J Med. 2016;374(23):2209-21.

9.

Döhner H, Weisdorf DJ, Bloomfield CD. Acute myeloid leukemia. N Engl J Med. 2015;373(12):1136-52. 10.

Piya S, Andreeff M, Borthakur G. Targeting autophagy to overcome chemoresistance in acute myleogenous leukemia. Autophagy. 2017;13(1):214-5.

11.

Auberger P, Puissant A. Autophagy, a key mechanism of oncogenesis and resistance in leukemia. Blood. 2017;129(5):547-52.

12.

Piya S, Kornblau SM, Ruvolo VR, Mu H, Ruvolo PP, McQueen T, et al. Atg7 suppression enhances chemotherapeutic agent sensitivity and overcomes stroma-mediated chemoresistance in acute myeloid leukemia. Blood. 2016;128(9):1260-9.

13.

Sehgal A, Konig H, Johnson D, Tang D, Amaravadi R, Boyiadzis M, et al. You eat what you are: autophagy inhibition as a therapeutic strategy in leukemia. Leukemia. 2015;29(3):517.

14.

Watson AS, Riffelmacher T, Stranks A, Williams O, De Boer J, Cain K, et al. Autophagy limits proliferation and glycolytic metabolism in acute myeloid leukemia. Cell death discovery. 2015;1:15008. 15.

Luo C, Li Y, Wang H, Feng Z, Li Y, Long J, et al. Mitochondrial accumulation under oxidative stress is due to defects in autophagy. Journal of cellular biochemistry. 2013;114(1):212-9.

16. 
Altman JK, Szilard A, Goussetis DJ, Sassano A, Colamonici M, Gounaris E, et al. Autophagy is a survival mechanism of acute myelogenous leukemia precursors during dual mTORC2/mTORC1 targeting. Clin Cancer Res. 2014;20(9):2400-9.

17.

Mahalingam D, Mita M, Sarantopoulos J, Wood L, Amaravadi RK, Davis LE, et al. Combined autophagy and HDAC inhibition: a phase I safety, tolerability, pharmacokinetic, and pharmacodynamic analysis of hydroxychloroquine in combination with the HDAC inhibitor vorinostat in patients with advanced solid tumors. Autophagy. 2014;10(8):1403-14.

18.

Zhang F, Zhu F-B, Li J-J, Zhang P-P, Zhu J-F. Hyperoside enhances the suppressive effects of arsenic trioxide on acute myeloid leukemia cells. Int J Clin Exp Med. 2015;8(9):15290.

19.

Haghi A, Salami M, Kian MM, Nikbakht M, Mohammadi S, Chahardouli B, et al. Effects of Sorafenib and Arsenic Trioxide on U937 and KG-1 Cell Lines: Apoptosis or Autophagy? Cell journal. 2020;22(3):253.

20.

Mohammadi MK, Haghi A, Salami M, Chahardouli B, Rostami S, Malekzadeh K, et al. Arsenic Trioxide and Thalidomide Combination Induces Autophagy Along with Apoptosis in Acute Myeloid Cell Lines. Cell journal. 2020;22(2):193-202.

21.

Jin J, Britschgi A, Schläfli AM, Humbert M, Shan-Krauer D, Batliner J, et al. Low Autophagy (ATG) Gene Expression Is Associated with an Immature AML Blast Cell Phenotype and Can Be Restored during AML Differentiation Therapy. Oxidative medicine and cellular longevity. 2018;2018.

22.

Moosavi MA, Djavaheri-Mergny M. Autophagy. New Insights into Mechanisms of Action and Resistance of Treatment in Acute Promyelocytic leukemia. Int J Mol Sci. 2019;20(14):3559.

23.

Mugoni V, Panella R, Cheloni G, Chen M, Pozdnyakova O, Stroopinsky D, et al. Vulnerabilities in mIDH2 AML confer sensitivity to APL-like targeted combination therapy. Cell research. 2019;29(6):446.

24.

Li C, Liu Y, Liu H, Zhang W, Shen C, Cho K, et al. Impact of autophagy inhibition at different stages on cytotoxic effect of autophagy inducer in glioblastoma cells. Cell Physiol Biochem. 2015;35(4):1303-16. 25.

Kong X, Xu X, Yan Y, Guo F, Li J, Hu Y, et al. Estrogen regulates the tumour suppressor MiRNA-30c and its target gene, MTA-1, in endometrial cancer. PLoS One. 2014;9(3):e90810.

26.

Mohammadi S, Ghaffari SH, Shaiegan M, Zarif MN, Nikbakht M, Birgani SA, et al. Acquired expression of osteopontin selectively promotes enrichment of leukemia stem cells through AKT/mTOR/PTEN/ $\beta$-catenin pathways in AML cells. Life sciences. 2016;152:190-8.

27. 
Zhao Y, Yang J, Liao W, Liu X, Zhang H, Wang S, et al. Cytosolic FoxO1 is essential for the induction of autophagy and tumour suppressor activity. Nat Cell Biol. 2010;12(7):665-75.

28.

Gao W, Shen Z, Shang L, Wang X. Upregulation of human autophagy-initiation kinase ULK1 by tumor suppressor p53 contributes to DNA-damage-induced cell death. Cell Death Differentiation. 2011;18(10):1598-607.

29.

Metz P, Chiramel A, Chatel-Chaix L, Alvisi G, Bankhead P, Mora-Rodríguez R, et al. Dengue virus inhibition of autophagic flux and dependency of viral replication on proteasomal degradation of the autophagy receptor p62. Journal of virology. 2015;89(15):8026-41.

30 .

Demishtein A, Fraiberg M, Berko D, Tirosh B, Elazar Z, Navon A. SQSTM1/p62-mediated autophagy compensates for loss of proteasome polyubiquitin recruiting capacity. Autophagy. 2017;13(10):1697708.

31.

Wei S, Wang Y, Chai Q, Fang Q, Zhang Y, Wang J. Potential crosstalk of Ca2+-ROS-dependent mechanism involved in apoptosis of Kasumi-1 cells mediated by heme oxygenase- 1 small interfering RNA. Int $J$ Oncol. 2014;45(6):2373-84.

32.

Fakhimahmadi A, Nazmi F, Rahmati M, Bonab NM, Hashemi M, Moosavi MA. Nucleostemin silencing induces differentiation and potentiates all-trans-retinoic acid effects in human acute promyelocytic leukemia NB4 cells via autophagy. Leukemia research. 2017;63:15-21.

33.

Zhang X-j, Chen S, Huang K-x. Le W-d. Why should autophagic flux be assessed? Acta Pharmacol Sin. 2013;34(5):595.

34.

Galluzzi L, Bravo-San Pedro JM, Levine B, Green DR, Kroemer G. Pharmacological modulation of autophagy: therapeutic potential and persisting obstacles. Nature reviews Drug discovery. 2017;16(7):487.

35.

Levy JMM, Towers CG, Thorburn A. Targeting autophagy in cancer. Nat Rev Cancer. 2017;17(9):528. 36.

Poklepovic A, Gewirtz DA. Outcome of early clinical trials of the combination of hydroxychloroquine with chemotherapy in cancer. Autophagy. 2014;10(8):1478-80.

37.

Chude C, Amaravadi R. Targeting autophagy in cancer: update on clinical trials and novel inhibitors. Int J Mol Sci. 2017;18(6):1279.

38.

Levy JMM, Thompson JC, Griesinger AM, Amani V, Donson AM, Birks DK, et al. Autophagy inhibition improves chemosensitivity in BRAFV600E brain tumors. Cancer discovery. 2014;4(7):773-80. 
39.

Maycotte P, Gearheart CM, Barnard R, Aryal S, Levy JMM, Fosmire SP, et al. STAT3-mediated autophagy dependence identifies subtypes of breast cancer where autophagy inhibition can be efficacious. Cancer research. 2014;74(9):2579-90.

40.

Baquero P, Dawson A, Mukhopadhyay A, Kuntz EM, Mitchell R, Olivares O, et al. Targeting quiescent leukemic stem cells using second generation autophagy inhibitors. Leukemia. 2018:1.

41.

Rothe K, Porter V, Jiang X. Current Outlook on Autophagy in Human Leukemia: Foe in Cancer Stem Cells and Drug Resistance, Friend in New Therapeutic Interventions. Int J Mol Sci. 2019;20(3):461.

42.

Baquero P, Dawson A, Mukhopadhyay A, Kuntz EM, Mitchell R, Olivares O, et al. Targeting quiescent leukemic stem cells using second generation autophagy inhibitors. Leukemia. 2019;33(4):981.

43.

Bellodi C, Lidonnici MR, Hamilton A, Helgason GV, Soliera AR, Ronchetti M, et al. Targeting autophagy potentiates tyrosine kinase inhibitor-induced cell death in Philadelphia chromosome-positive cells, including primary CML stem cells. J Clin Investig. 2009;119(5):1109.

44.

Orfali N, McKenna SL, Cahill MR, Gudas LJ, Mongan NP. Retinoid receptor signaling and autophagy in acute promyelocytic leukemia. Experimental cell research. 2014;324(1):1-12.

45.

Booth LA, Tavallai S, Hamed HA, Cruickshanks N, Dent P. The role of cell signalling in the crosstalk between autophagy and apoptosis. Cellular signalling. 2014;26(3):549-55.

46.

Salazar M, Carracedo A, Salanueva ÍJ, Hernández-Tiedra S, Lorente M, Egia A, et al. Cannabinoid action induces autophagy-mediated cell death through stimulation of ER stress in human glioma cells. J Clin Investig. 2009;119(5):1359-72.

47.

Koike M, Shibata M, Tadakoshi M, Gotoh K, Komatsu M, Waguri S, et al. Inhibition of autophagy prevents hippocampal pyramidal neuron death after hypoxic-ischemic injury. Am J Pathol. 2008;172(2):454-69. 48.

Brigger D, Schläfli A, Garattini E, Tschan M. Activation of RARa induces autophagy in SKBR3 breast cancer cells and depletion of key autophagy genes enhances ATRA toxicity. Cell death disease. 2015;6(8):e1861.

49.

Wang Z, Cao L, Kang R, Yang M, Liu L, Zhao Y, et al. Autophagy regulates myeloid cell differentiation by p62/SQSTM1-mediated degradation of PML-RARa oncoprotein. Autophagy. 2011;7(4):401-11. 50 .

Bonapace L, Bornhauser BC, Schmitz M, Cario G, Ziegler U, Niggli FK, et al. Induction of autophagydependent necroptosis is required for childhood acute lymphoblastic leukemia cells to overcome 
glucocorticoid resistance. J Clin Investig. 2010;120(4):1310-23.

51.

Kim Y, Eom J-I, Jeung H-K, Jang JE, Kim JS, Cheong J-W, et al. Induction of cytosine arabinoside-resistant human myeloid leukemia cell death through autophagy regulation by hydroxychloroquine. Biomed Pharmacother. 2015;73:87-96.

52.

Folkerts $\mathrm{H}$, Hilgendorf S, Wierenga AT, Jaques J, Mulder AB, Coffer PJ, et al. Inhibition of autophagy as a treatment strategy for p53 wild-type acute myeloid leukemia. Cell death disease. 2017;8(7):e2927.

\section{Figures}


a

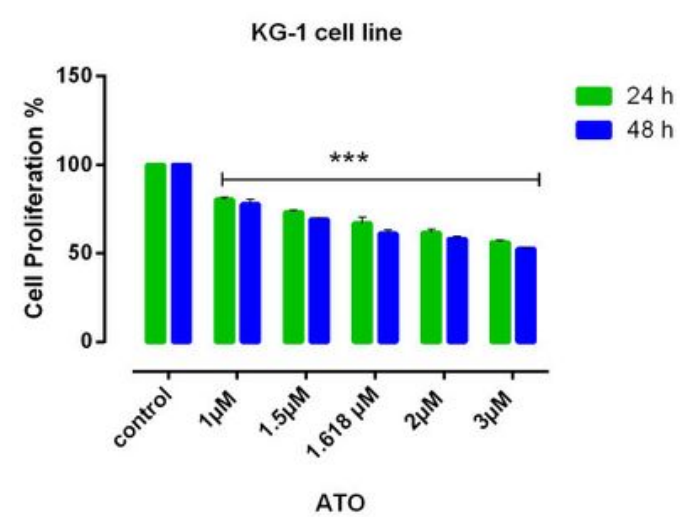

b

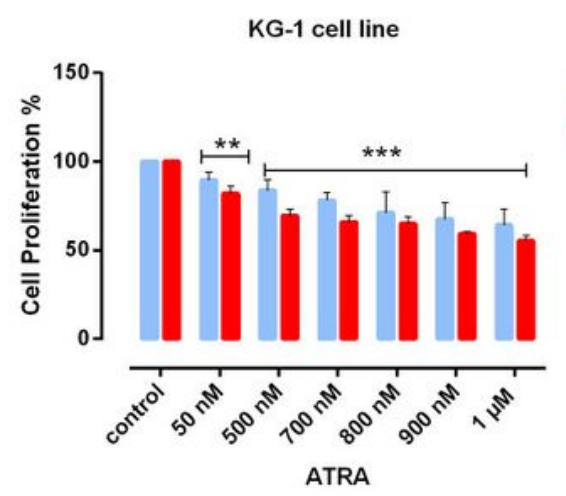

C

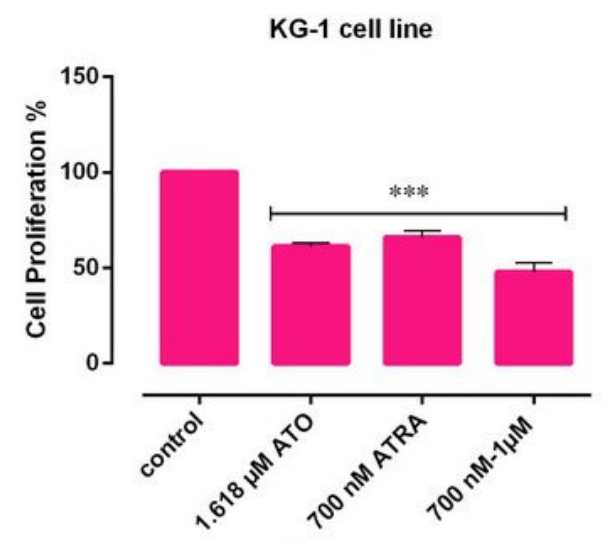

ATO+ATRA/ $48 \mathrm{~h}$ d

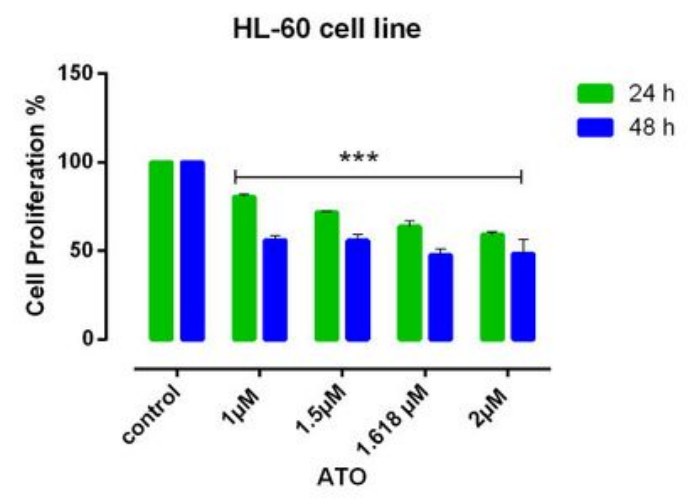

e

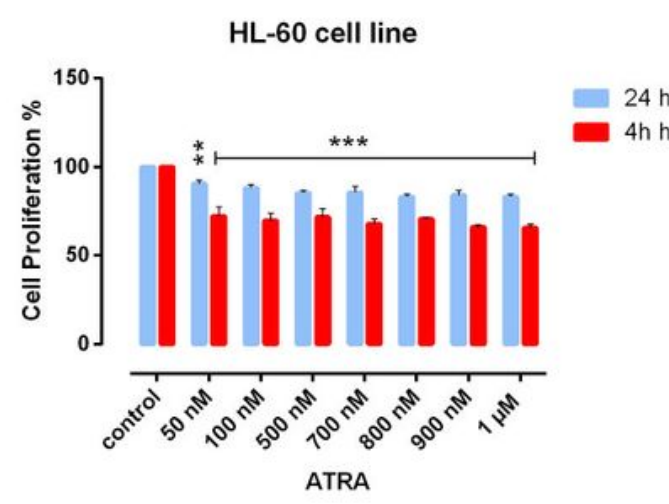

f

HL-60 cell line

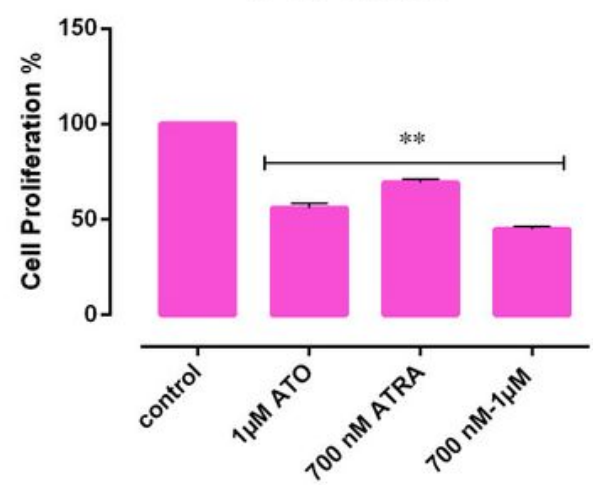

ATO+ATRA/ 48 h

\section{Figure 1}

Cell proliferation in KG-1 and HL-60. The anti-proliferative effects of ATO (a), ATRA (b) and their combinations (c) on KG-1 and the anti-proliferative effects of ATO (d), ATRA (e) and their combinations (f) on HL-60 were assessed by MTT assay after $24 \mathrm{~h}$ and $48 \mathrm{~h}$ treatment. Data are mean \pm S.E of three independent experiments. Statistical significance were defined at ${ }^{*} P<0.05,{ }^{*} \mathrm{P}<0.01$ and $\star \star \star P<0.001$ compared to control. 
a)
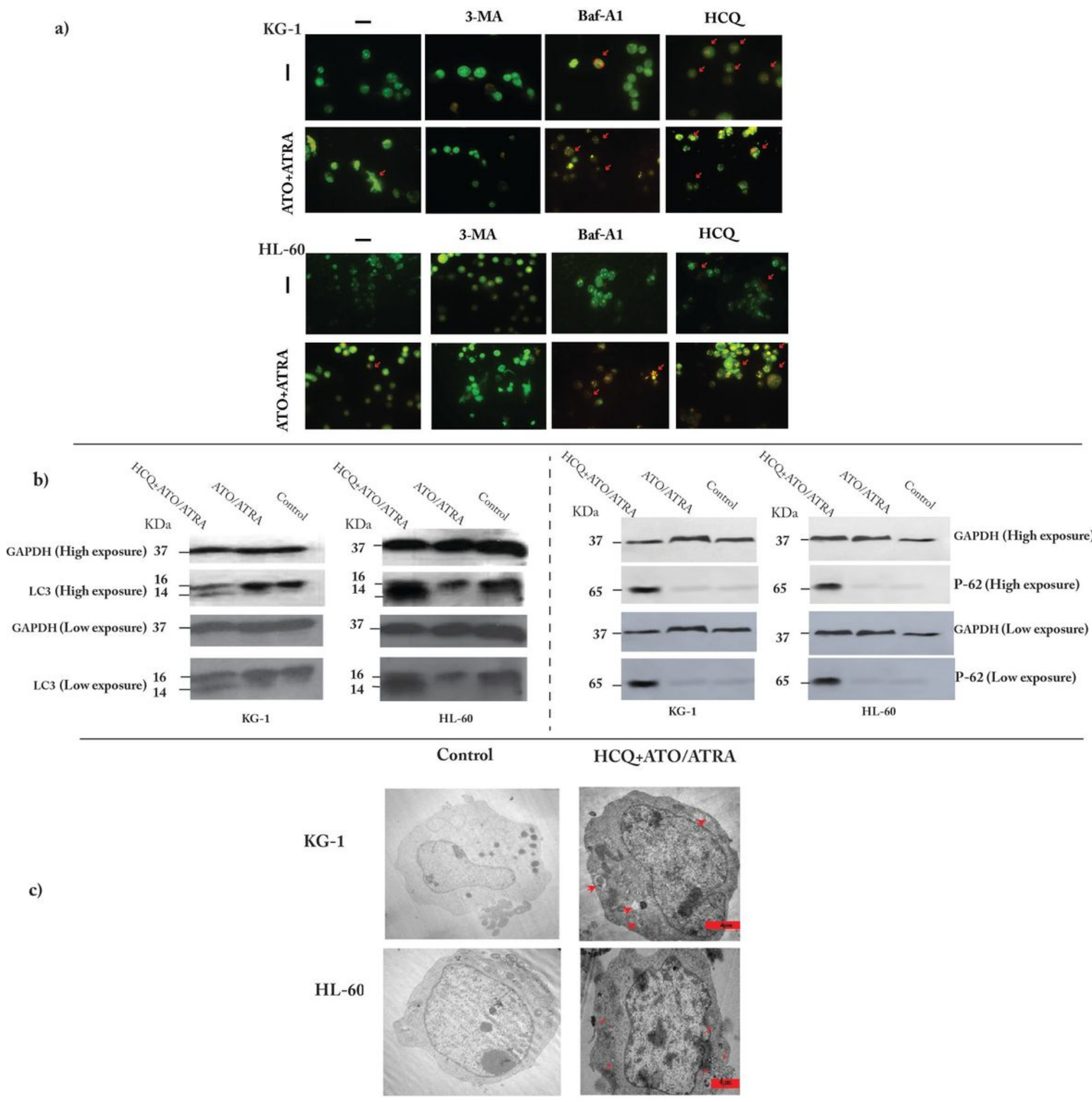

Figure 2

Autophagy markers are induced in HCQ and BAF-A1 treated leukemia cells. (a) The formation of AVO induced by HCQ+ATO/ATRA and BAf-A1+ ATO/ATRA. Green and red fluorescence in treated cells stained with acridine orange were observed under a fluorescence microscope. (b) Cell proteins were evaluated using western blot analysis to investigate the conversion of LC3-I to LC3-II and protein expression of P62. Full-length blots can be find in a Supplementary Information file. (c) Ultra-structural inspection using TEM 
of KG-1 and HL-60 cells treated for $48 \mathrm{~h}$ with or without HCQ+ATO/ATRA. The arrow indicates condensed chromatin and autophagosomes.
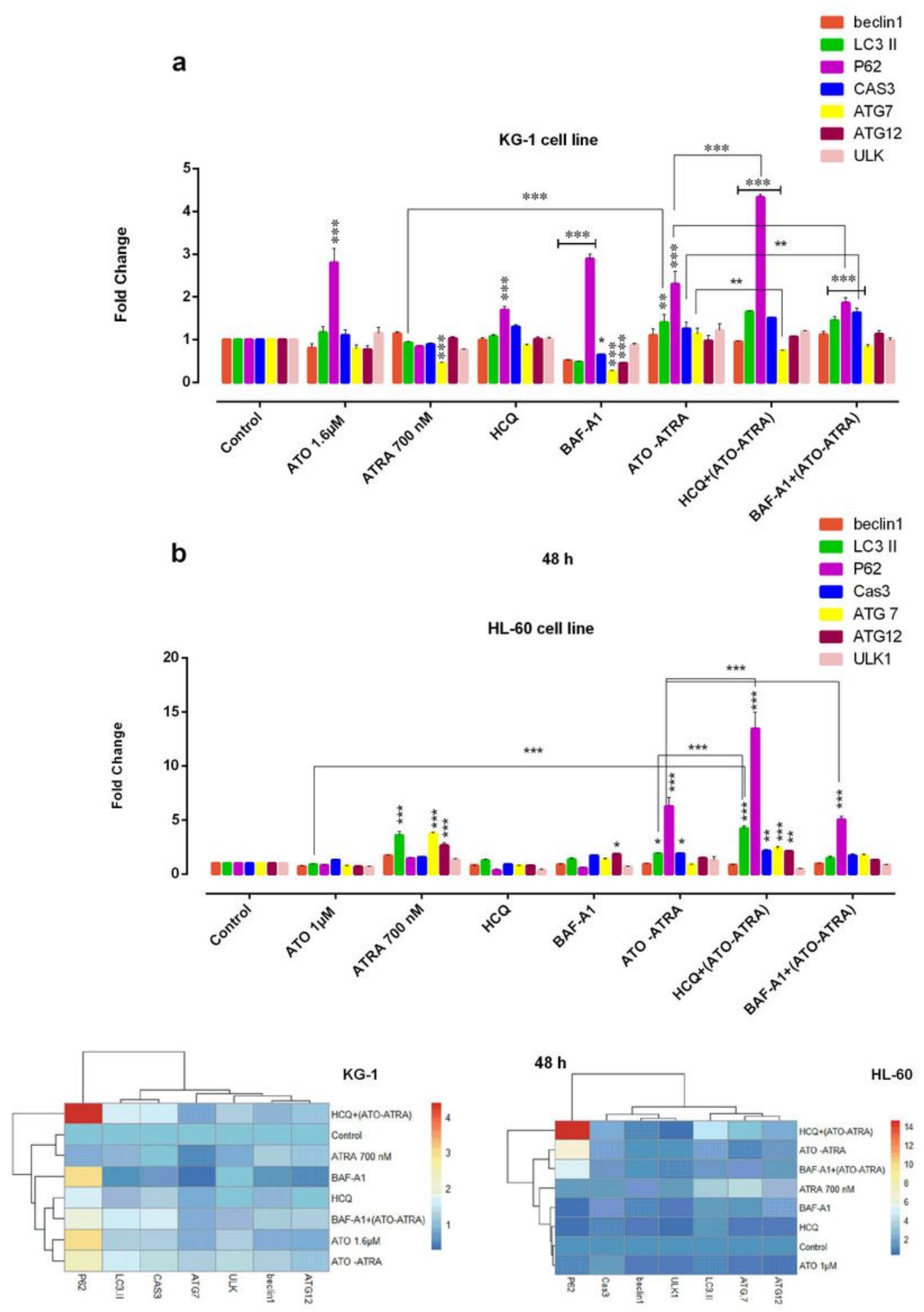

Figure 3

The mRNA expression in KG-1(a) and HL-60 (b) cell lines. The effects of ATO, ATRA, autophagy inhibitors (BAF-A1 and HCQ) and their combination on the mRNA level of indicated genes in cited cell lines were determined by real-time PCR. Values were normalized using the expression of the housekeeping HPRT. 
Values are given as mean \pm S.E. of independent experiments. Statistical significance were defined at ${ }^{*} \mathrm{P}<0.05,{ }^{*} \mathrm{P}<0.01$ and ${ }^{*} * * \mathrm{P}<0.001$
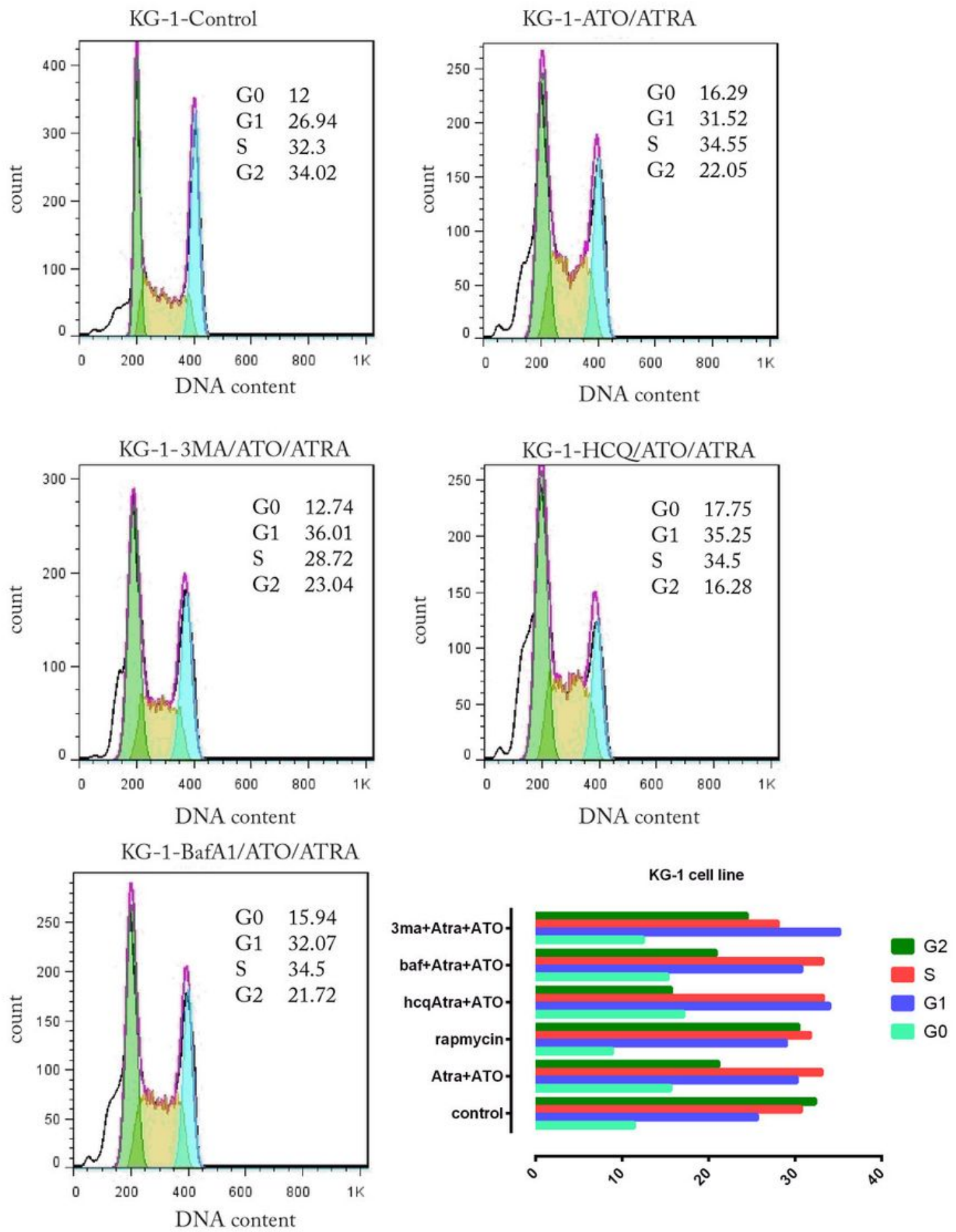

Figure 4

Cell cycle analysis in KG-1 cell line. Our result showed changes in the proportion of cells at the G0/G1 phase of the cell cycle in control: 38.94, HCQ+ATO/ATRA: 61, BafA1+ATO/ATRA: 48.01 and 3MA+ATO/ATRA: 48.75. 

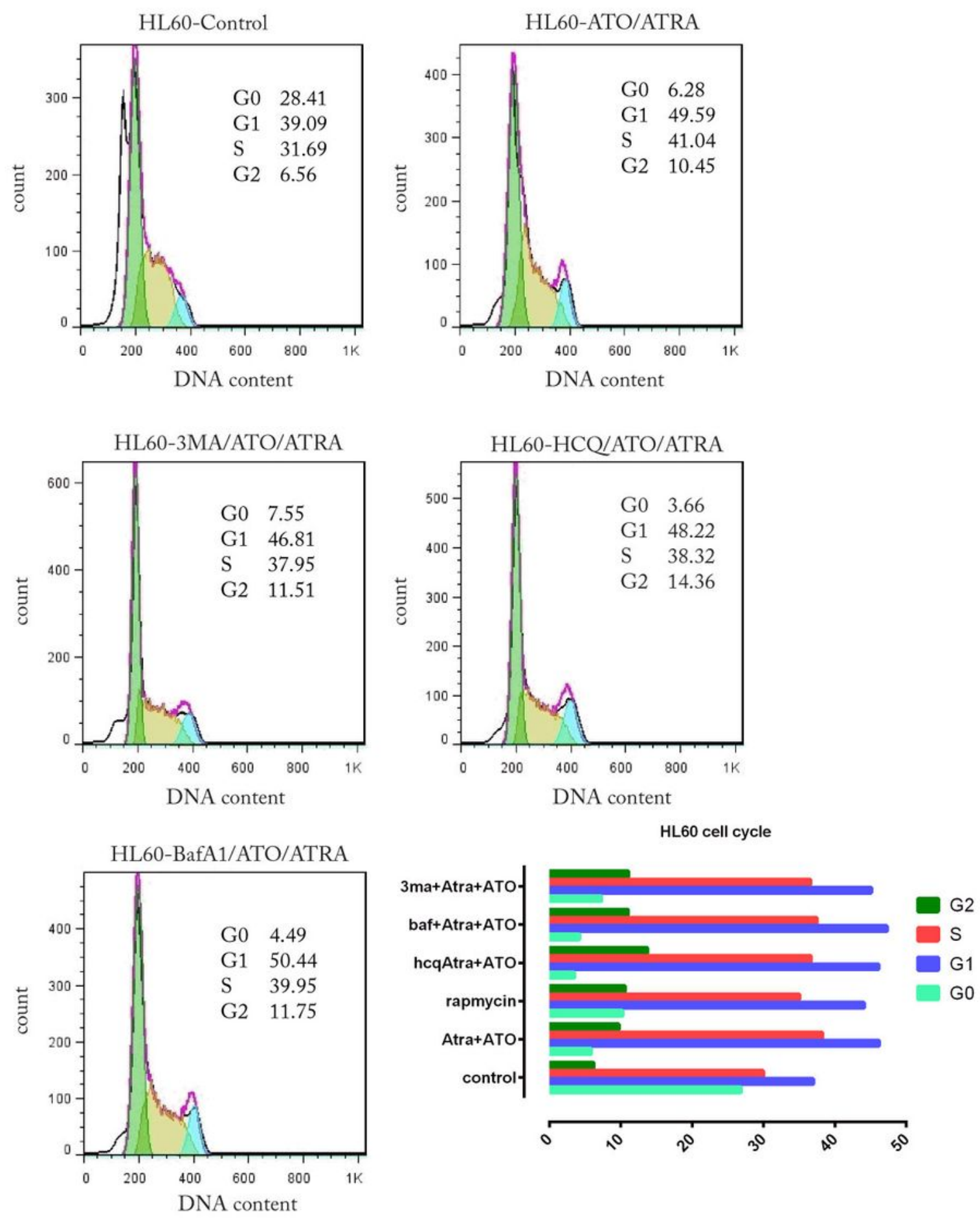

\section{Figure 5}

Cell cycle analysis in HL-60 cell line. Our result showed changes in the proportion of cells at the G0/G1 phase of the cell cycle in control: 67.50, HCQ+ATO/ATRA: 51.88 BafA1+ATO/ATRA: 54.93 and 3MA+ATO/ATRA: 54.36. 


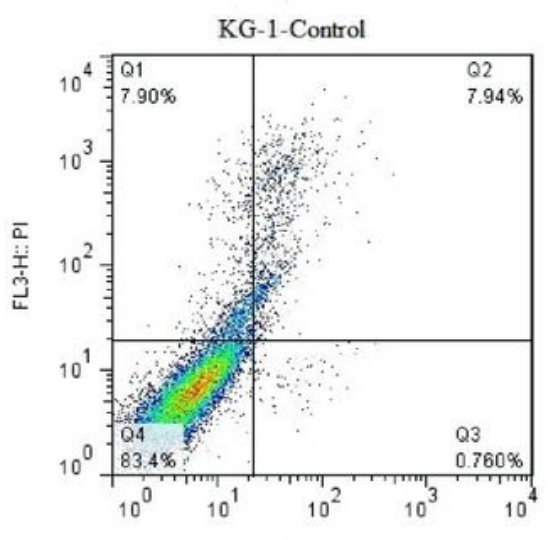

FL1-H.: Annexin V-FITC
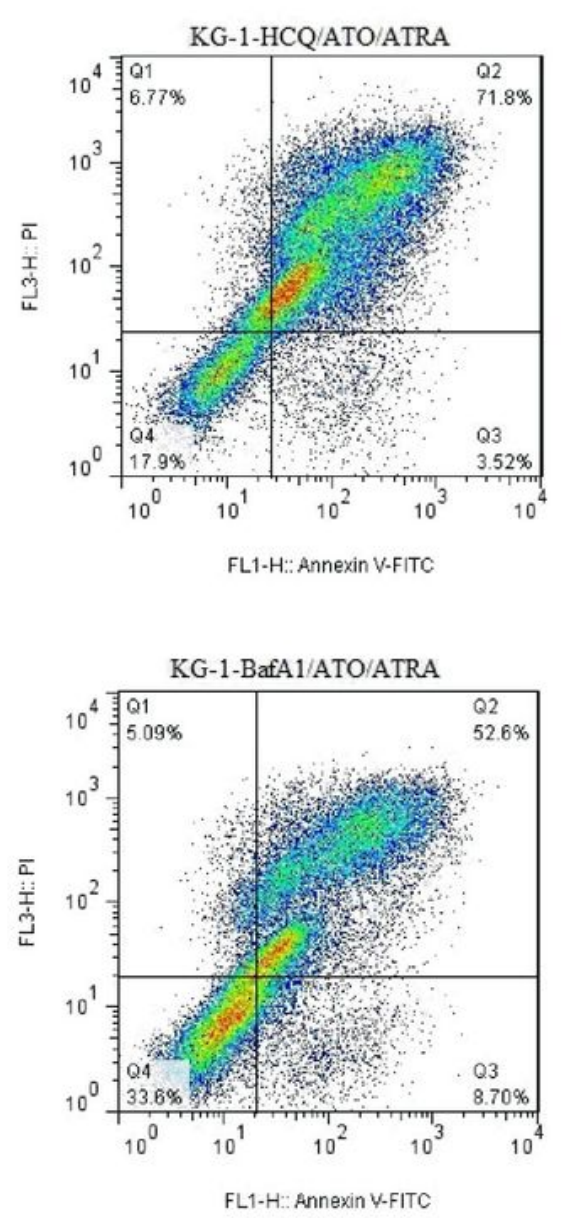
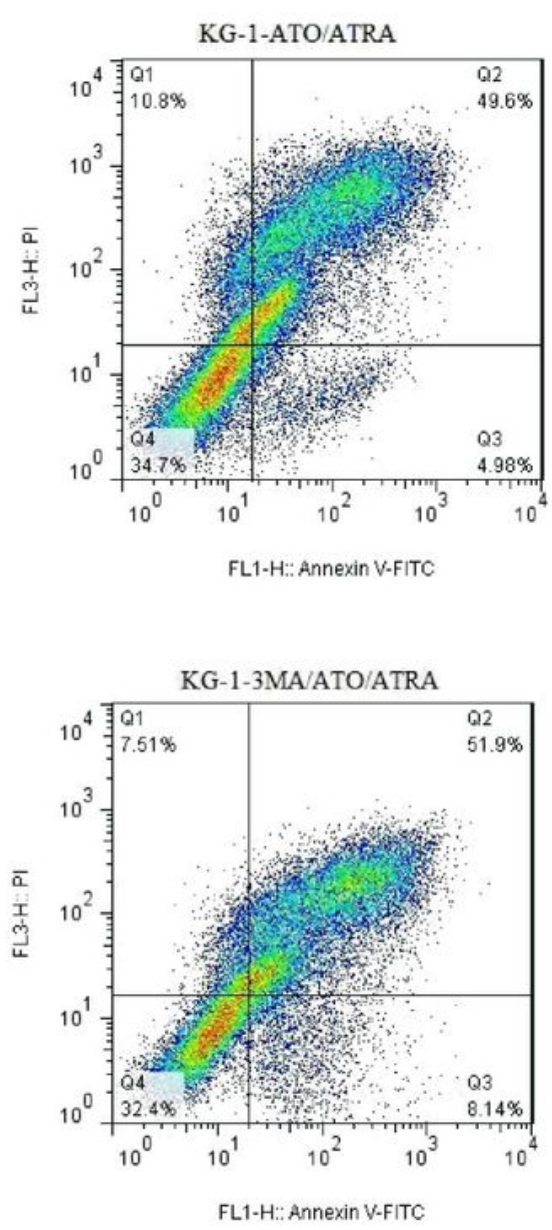

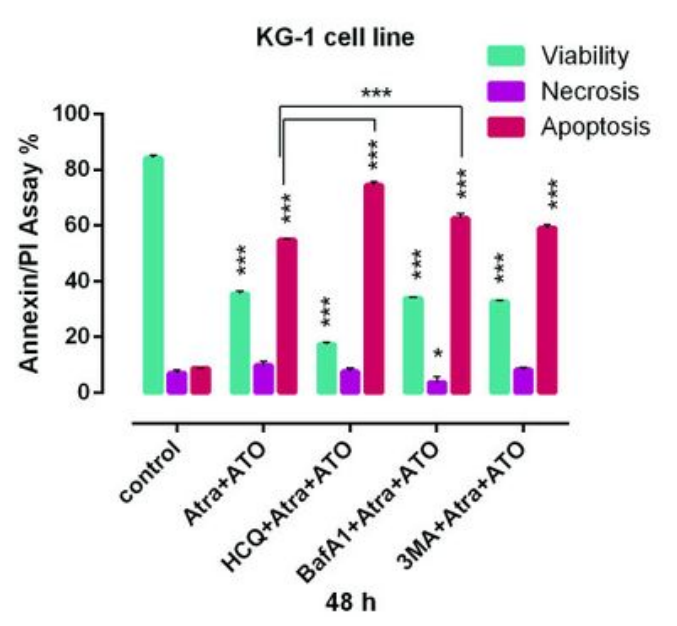

\section{Figure 6}

Apoptosis assay in KG-1 after $48 \mathrm{~h}$. Data are mean $\pm \mathrm{S}$.E of three independent experiments. Statistical significance were defined at ${ }^{*} P<0.05, * * P<0.01$ and $* \star \star P<0.001$. 

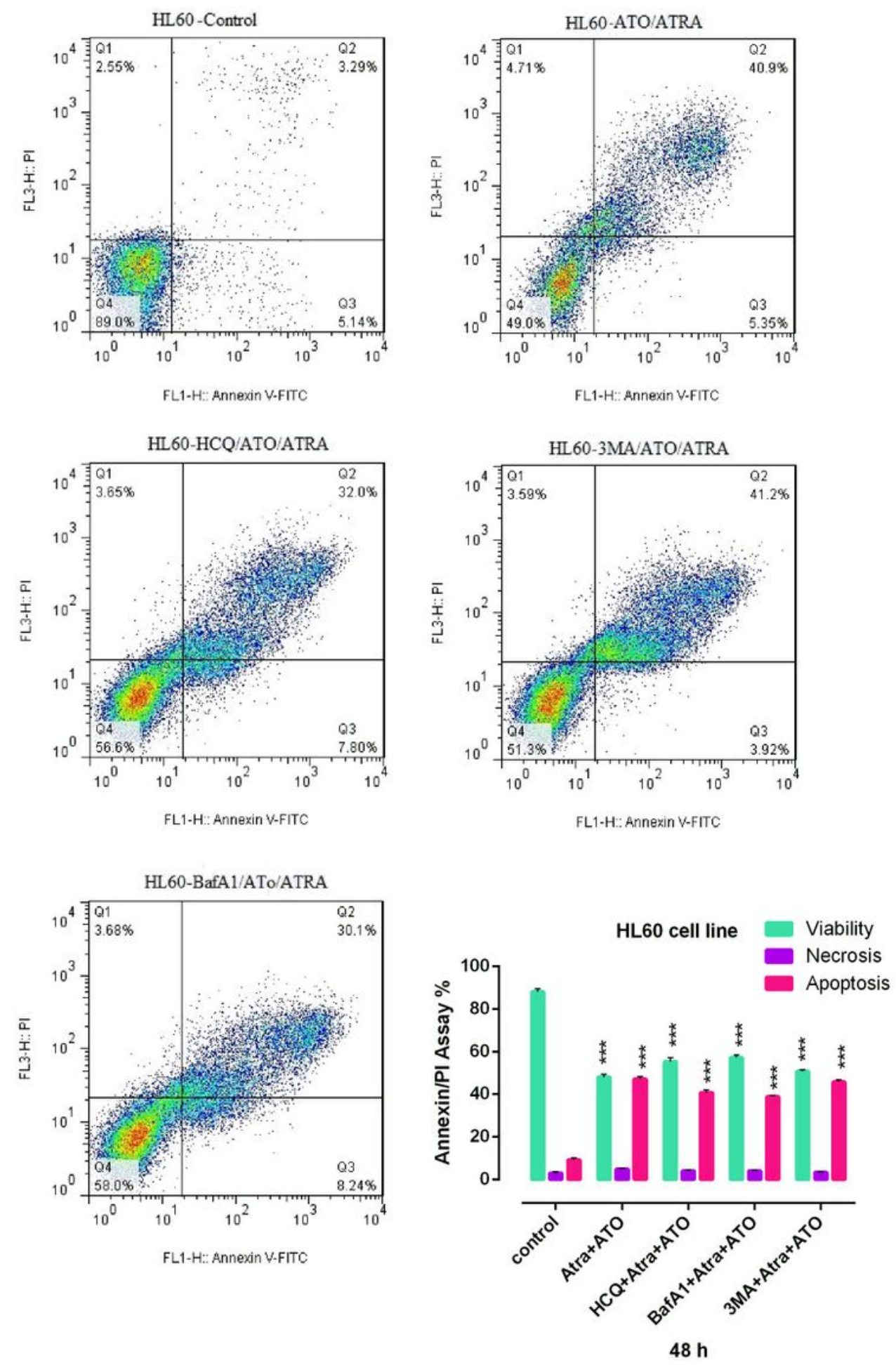

\section{Figure 7}

Apoptosis assay in HL-60 after $48 \mathrm{~h}$. Data are mean \pm S.E of three independent experiments. Statistical significance were defined at ${ }^{*} P<0.05,{ }^{*} \mathrm{P}<0.01$ and ${ }^{*} * \mathrm{P}<0.001$.

\section{Supplementary Files}


This is a list of supplementary files associated with this preprint. Click to download.

- supplementaryinformation.pdf 